\title{
Hypermethylation of collagen $\alpha 2$ (I) gene (COL1A2) is an independent predictor of survival in head and neck cancer
}

\author{
Kiyoshi Misawa ${ }^{\mathrm{a}, *}$, Takeharu Kanazawa ${ }^{\mathrm{b}}$, Yuki Misawa ${ }^{\mathrm{a}}$, Atsushi Imai ${ }^{\mathrm{a}}$, Shiori Endo ${ }^{\mathrm{a}}$, \\ Katsura Hakamada ${ }^{\mathrm{a}}$ and Hiroyuki Mineta ${ }^{\mathrm{a}}$ \\ ${ }^{a}$ Department of Otolaryngology/Head and Neck Surgery, Hamamatsu University School of Medicine, Shizuoka, \\ Japan \\ ${ }^{\mathrm{b}}$ Department of Otolaryngology/Head and Neck Surgery, Jichi Medical University, Tochigi, Japan
}

\begin{abstract}
Objectives: Collagen production plays a role in the development of tumors from cancer cells. The aim of the present study is to examine the involvement of epigenetic alteration of Collagen $\alpha 2$ (I) (COL1A2) gene expression in cases of head and neck squamous cell carcinoma (HNSCC).

Methods: COL1A2 expression was examined in a panel of cell lines using RT-PCR. The methylation status of the COL1A2 promoter was studied using bisulfate sequencing and methylation-specific PCR (MSP).

Results: COL1A2 expression was absent in 6 of 11 (54.5\%) UM-SCC cell lines, whereas three nonmalignant cell lines had stable expressions. MSP analysis showed that 46/98 (46.9\%) contained methylated alleles. COL1A2 methylation was significantly correlated with tumor size $(P=0.041)$, lymph node status $(P=0.008)$, tumor stage $(P=0.011), H$-cadherin methylation $(P=0.039)$ and disease-free survival $(P=0.005)$. On multivariate Cox proportional hazard regression, which included age, sex, smoking status, and alcohol exposure, both tumor stage and COL1A2 methylation remained independent prognostic factors. Conclusions: This study suggests that $\mathrm{CpG}$ hypermethylation is a likely mechanism of COL1A2 gene inactivation, supporting the hypothesis that the COL1A2 gene may play a role in the tumorigenesis of HNSCC and may serve as an important biomarker.
\end{abstract}

Keywords: COL1A2, DNA methylation, CpG island, head and neck cancer, 5-azacytidine

\section{Introduction}

Squamous cell carcinoma of the head and neck region (HNSCC) is the sixth most frequent cancer and affects $\sim 500,000$ patients per year worldwide [1]. Various factors are linked to the development of HNSCC; sex, tobacco smoking, alcohol consumption, and HPV infection are major risk factors for the disease [2]. The prognosis for patients with HNSCC is still poor today despite tremendous technical advances in surgical treat-

\footnotetext{
* Corresponding author: Kiyoshi Misawa, Department of Otolaryngology/Head and Neck Surgery, Hamamatsu University School of Medicine, 1-20-1 Handayama, Shizuoka 431-3192, Japan. Tel.: +81 53435 2252; Fax: +81 53435 2253; E-mail: kiyoshim@ hamamed.ac.jp.
}

ment, radiotherapy, and chemotherapy [3]. This dismal survival could be improved through earlier detection or through identification of prognostic markers, which could identify subsets of patients with worse prognoses who might benefit from a more aggressive treatment strategy.

Epigenetics is one of the most promising and expanding fields in the current biomedical research landscape [4]. Epigenetic silencing is involved in the initiation and progression of several types of cancer. In HNSCC, some tumor suppressor genes, such as $p 16$ [5], E-cadherin [6], and RASSF1A [7], have been found to harbor hypermethylation of $\mathrm{CpG}$ islands within the promoter regions. Loss of gene function by transcriptional silencing of selected genes may play a crucial role in the development and progression of cancers [8]. The 
detection of methylated genes is an attractive biomarker for risk assessment, early detection, and monitoring of prognosis, as well as the prevention of HNSCC.

Collagen is a large family of at least 28 extracellular matrix proteins that play vital structural and physiological roles in maintaining the integrity of and contributing to the homeostasis of the human body [9]. Type I collagen, the most abundant collagen molecule, normally consists of a heterotrimer of two $\alpha 1$ (I) (produced by the COL1A1) chains and one $\alpha 2$ (I) (produced by the COL1A2) chain [10]. Structural integrity and coordinated biosynthesis of the two chains are critically important for tissue morphogenesis, growth, homeostasis, and repair [11]. Hypermethylation of COL1A2 has been described in many cancers, mainly adenocarcinomas, including colorectal cancer [12], melanoma [13], bladder cancer [14], neuroblastoma [15], medulloblastoma [16,17], breast cancer [18], and hepatoma [19]. The investigation for oncogenic mechanism by COL1A2 gene inactivation was also recently progressing. Mori et al. reported that COL1A2 gene inactivation through CpG hypermethylation may contribute to proliferation and migration activity of bladder cancer [14]. Despite of accumulated knowledges in adenocarcinoma, hypermethylation of COL1A2 in squamous cell carcinoma (SCC) such as head and neck, esophagus, lung and cervix, is an area that still remains to be explored.

The aim of the present study is to evaluate COL1A2 methylation in large panels of primary HNSCC (that is typical SCC specimens). We demonstrate that loss of COL1A2 expression is associated with hypermethylation of key $\mathrm{CpG}$ sites within transcription factor binding domains and that expression can be restored after treatment with the demethylating agent, 5-azacytidine, and the histone deacetylase inhibitor, trichostatin A (TSA). Furthermore, assessment of primary tumor specimens confirm that hypermethylation is as common in patient tumors and is directly associated with tumor size and metastasis. This study suggests that hypermethylation of COL1A2 gene in the primary tumor is an independent predictor of survival in head and neck cancer.

\section{Materials and methods}

\subsection{Tumor samples and cell lines}

Tumor specimens were obtained at surgery from 98 primary HNSCC samples. All patients were treated at the Department of Otolaryngology, Hamamatsu Uni- versity School of Medicine. Clinical information including age, sex, tumor site, smoking status, alcohol intake, tumor size, lymph node status, and stage grouping were obtained from the clinical records. The average patient age was 63.6 years (range, 39-93 years), and the male: female ratio was $80: 18$. The primary tumor was located in the oral cavity $(n=39)$, hypopharynx $(n=25)$, larynx $(n=20)$, and oropharynx $(n=14)$. DNA and cDNA from 11 UM-SCC cell lines and 2 fibroblasts cell lines established from patients at the University of Michigan were kindly provided by Dr. Thomas E. Carey of the University of Michigan. Normal human keratinocytes (NHK) were a gift from Dr. No Hee Park of the UCLA School of Dentistry [20].

\subsection{Bisulfite modification and MSP analysis}

Bisulfite modification of genomic DNA was carried out as described previously [21]. Bisulfite-treated DNA was amplified by PCR with two designed pairs of methylation-specific PCR (MSP/UMSP) primers for the promoter region of the COL1A2 gene. The MSP primer set was 5'-ACGGTAGTAGGAGGTTTCGG-3' (forward) and 5'-CGCAAAACCCCTAAATCACCGA CG-3' (reverse). The UMSP primer set was 5'-ATG GTAGTAGGAGGTTTTGG-3' (forward) and 5'-CA CAAAACCCCTAAATCACCAACA-3' (reverse). The PCR conditions were: $94^{\circ} \mathrm{C}$ for $5 \mathrm{~min} ; 39$ cycles at $94^{\circ} \mathrm{C}$ for $30 \mathrm{~s}, 58^{\circ} \mathrm{C}$ (for detection of methylated DNA) or $54^{\circ} \mathrm{C}$ (for detection of unmethylated DNA) for $30 \mathrm{~s}$, and $72^{\circ} \mathrm{C}$ for $40 \mathrm{~s}$; and a final extension at $72^{\circ} \mathrm{C}$ for $5 \mathrm{~min}$. The PCR products were $82 \mathrm{bp}$ long. To analyze the methylation status of the $p 16$ gene [5], E-cadherin gene [6], RASSF1A gene [7], H-cadherin gene [22], DAPK gene [23], MGMT gene [23], and $D C C$ gene [24], primers and conditions as described previously were used. The PCR products were separated by electrophoresis through a $9 \%$ polyacrylamide gel and stained with ethidium bromide.

\subsection{Bisulfite sequencing analysis for COL1A2}

Bisulfite-treated DNA was amplified by bisulfite sequencing PCR (BSP) with primers that were specific for modified upper strand DNAs but did not contain any $\mathrm{CpG}$ sites. The BSP primer set was 5'-GTGTTTTTAAATTTGGAAAGGG-3' (forward) and 5'-CTACAAACAACAACAAAATCC-3' (reverse). The PCR conditions were: $94^{\circ} \mathrm{C}$ for $5 \mathrm{~min}$; 45 cycles at $94^{\circ} \mathrm{C}$ for $30 \mathrm{~s}, 54^{\circ} \mathrm{C}$ for $30 \mathrm{~s}$ and $72^{\circ} \mathrm{C}$ for $40 \mathrm{~s}$; and a final extension at $72^{\circ} \mathrm{C}$ for $5 \mathrm{~min}$. The PCR products were 504 bp long. Bisulfite sequencing analysis was carried out as described previously [21]. 
A

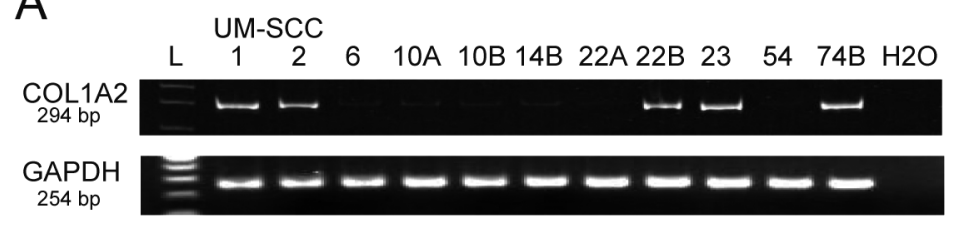

B

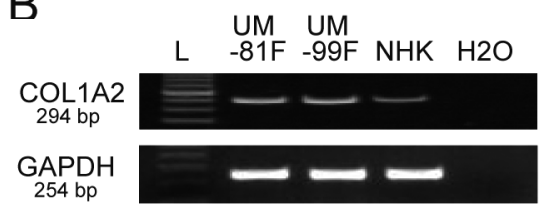

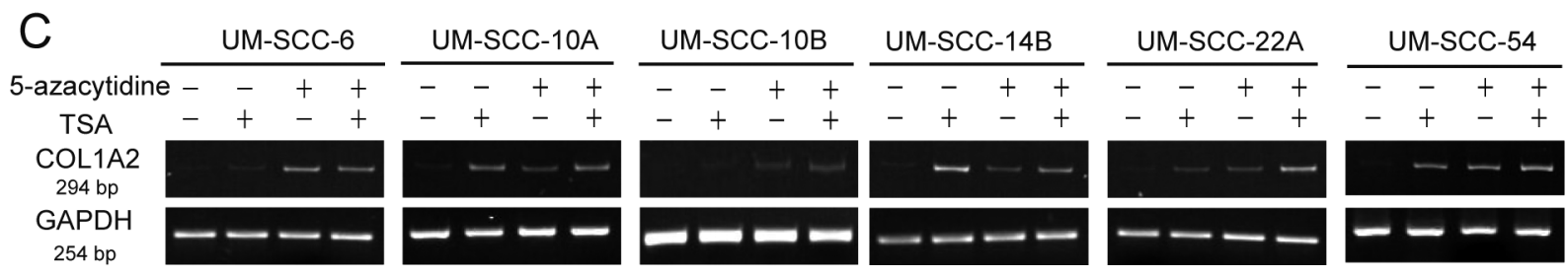

Fig. 1. COL1A2 expression by RT-PCR. (A) Representative examples of RT-PCR for COL1A2 expression in UM-SCC cell lines. Amplification reactions were carried out for 35 cycles to identify cell lines with low or absent COL1A2 expression. The housekeeping gene GAPDH was run as a control for RNA integrity. (B) Representative examples of RT-PCR for COL1A2 expression in nonmalignant samples. (C) The effect of treatment with 5-azacytidine or trichostatin A or both on COL1A2 expression in six cell lines with densely methylated COL1A2 is shown using RT-PCR. Controls were cells treated similarly but without 5-azacytidine and trichostatin A.

\subsection{RT-PCR for COL1A2}

The primer sequences designed from the coding region of the human COL1A2 cDNA have been described previously [25]. The PCR products were separated by electrophoresis through a $9 \%$ polyacrylamide gel. Sense and antisense primers for the GAPDH gene used as an internal control have been described previously [21].

\subsection{Reactivation of COL1A2 expression}

Twelve hours after plating, cultures were incubated either for $48 \mathrm{~h}$ with 5-azacytidine $(15 \mu \mathrm{g} / \mathrm{ml}, 30 \mu \mathrm{g} / \mathrm{ml}$; Sigma, St. Louis, MO), an inhibitor of DNA methyltransferase, for $24 \mathrm{~h}$ with $300 \mathrm{nM}$ trichostatin A (TSA) (Sigma), an inhibitor of histone deacetylase, or for $48 \mathrm{~h}$ with 5 -azacytidine followed by $24 \mathrm{~h}$ incubation with TSA. The medium was then removed, and cultures were maintained in standard Dulbecco's modified Eagle's medium, which was replaced every other day [21].

\subsection{Statistical analysis}

For frequency analysis in contingency tables, statistical analyses of associations between variables were performed by Fisher's exact test. The disease-free interval was measured from the date of the treatment to the date when locoregional recurrence or distant metastasis was diagnosed. Disease-free survival probabilities were estimated by the Kaplan-Meier method, and the log-rank test was applied to assess the significance of differences among actuarial survival curves. Cox proportional hazards multivariate regression analysis, which involved age, sex, smoking status, alcohol intake, stage grouping, and COL1A2 methylation, was used to identify the predictive value of the prognostic factors $[6,26]$. A significant difference was identified when the probability was less than 0.05 . Statistical analysis was done with StatMate IV (ATMS Co., Ltd., Tokyo, Japan).

\section{Results}

\subsection{COL1A2 expressions and effect of treatment with 5-azacytidine and TSA}

A total of $11 \mathrm{UM}-\mathrm{SCC}$ cell lines were analyzed for COL1A2 expression using RT-PCR. COL1A2 expression was absent in 6 of $11(54.5 \%)$ UM-SCC cell lines (UM-SCC-6, 10A, 10B, 14B, 22A, and 54) after 35 cycles (Fig. 1A). RT-PCR amplification of RNA from normal control cell lines (UM-81F, UM-99F and NHK) as template yielded a good signal after 35 cycles, indicating that COL1A2 is expressed in these normal cells (Fig. 1B). To establish that methylation was responsible for silencing COL1A2 gene expression, six cell lines (UM-SCC-6, 10A, 10B, 14B, 22A, and 54) were treated. These cell lines, which showed the absence of COL1A2 expression and hypermethylation by bisulfite sequencing analysis, were cultured with 5-azacytidine alone, TSA alone, or 5-azacytidine plus TSA. This facilitated assessment of the effect of 
A

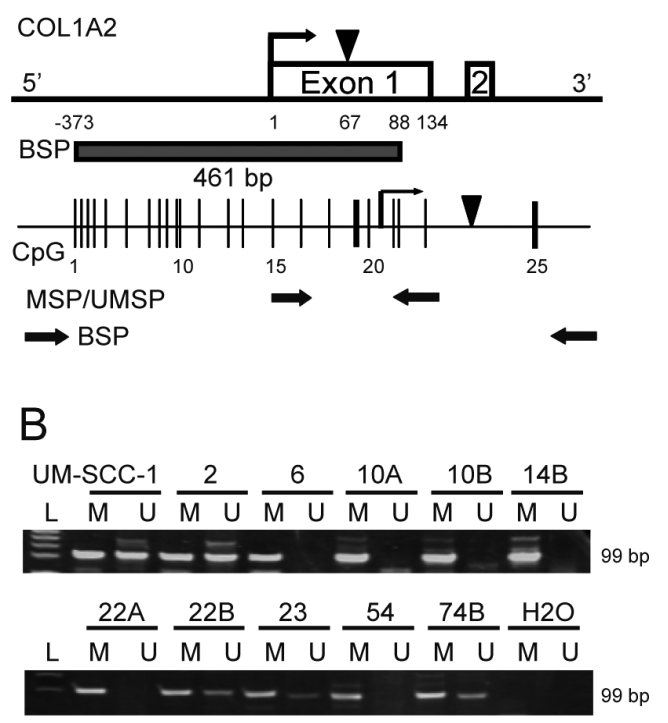

$\mathrm{C} \frac{\mathrm{H}-3}{\mathrm{M} U} \frac{\mathrm{H}-21}{\mathrm{M} U} \frac{\mathrm{H}-24}{\mathrm{M} U} \frac{\mathrm{H}-52}{\mathrm{M} U} \frac{\mathrm{H}-74}{\mathrm{MU}}$
$\mathrm{L} \frac{\mathrm{H}-27}{\mathrm{M} U} \frac{\mathrm{H}-33}{\mathrm{M} U} \frac{\mathrm{H}-68}{\mathrm{M} U} \frac{\mathrm{H}-99}{\mathrm{MU}} \frac{\mathrm{H} 2 \mathrm{bp}}{\mathrm{MU}}$
$=-$

Fig. 2. Diagrammatic representation of the COL1A2 gene and methylation analysis using the MSP assay. (A) The COL1A2 $\mathrm{CpG}$ sites within expanded views of the promoter region relative to the transcription start site are shown. Individual $\mathrm{CpG}$ sites are indicated as vertical lines. The brackets enclose the 461-bp region that includes the transcription start site and the 25 individual $\mathrm{CpG}$ sites that were examined for frequency of methylation. The relative locations of the primers used for MSP and bisulfite sequencing are shown with black arrows. The transcription start site is represented by a bent arrow. The translation start site is represented by an arrowhead. (B) Representative examples of MSP of COL1A2 in UM-SCC cell lines, showing samples that are fully methylated (UM-SCC-6, -10A, -10B, $-14 \mathrm{~B},-22 \mathrm{~A},-54)$ and partially methylated (UM-SCC-1, $-2,-22 \mathrm{~B},-23$, -74B). (C) Representative examples of MSP of COL1A2 in primary tumors from Hamamatsu University Hospital, showing samples that are methylated $(\mathrm{H}-3, \mathrm{H}-21, \mathrm{H}-24, \mathrm{H}-52, \mathrm{H}-74)$ and unmethylated (H-27, H-33, H-68, H-99).

demethylation induced by 5 -azacytidine and inhibition of histone deacetylase by TSA. All six cell lines demonstrated restored COL1A2 expression that correlated with the demethylation and histone acetylating signals (Fig. 1C).

\subsection{MSP analysis for COL1A2}

Each sample was tested with both sets of primers (MSP and UMSP) for the COL1A2 promoter region.
These primers were designed based on the bisulfite sequencing data. Forward primers for MSP and UMSP contain \#15 and $16 \mathrm{CpG}$ dinucleotides. Reverse primers for MSP and UMSP include \#21-23 CpG dinucleotides (Fig. 2A). The MSP assay for COL1A2 correlated with the expression status. In all cell lines with reduced expression (UM-SCC-6, 10A, 10B, 14B, 22A, and 54), only methylated alleles were detected. In cell lines with apparently normal COLIA2 mRNA levels (UM-SCC-1, 2, 22B, 23, and 74B), both alleles were detected (Fig. 2B). Among 98 primary HNSCC DNA samples tested, the COL1A2 promoter was methylated in $46(46.9 \%)$ cases and unmethylated in $52(53.1 \%)$. Methylation of COL1A2 was significantly correlated with tumor size $(P=0.041)$, lymph node status $(P=$ $0.008)$, and tumor stage $(P=0.011)$ (Fig. 2C, Table 1$)$.

\subsection{Bisulfite sequencing analysis}

These cell lines were analyzed for COL1A2 promoter region methylation status. Bisulfite sequencing was used to more precisely map and determine the density of methylation throughout the COL1A2 promoter (Fig. 3A). CpG sites \#1 to 20 were located upstream of TSS, and sites \#21 to 25 were located downstream of TSS. We sequenced at least seven clones for each of the 11 cell lines. Cell lines UM-SCC-6, 10A, 10B, 14B, $22 \mathrm{~A}$, and 54 had loss of COL1A2 expression, as demonstrated by RT-PCR, and high methylation levels $(62.9 \%$ to $90.5 \%$ ). Cell lines UM-SCC-2, 22B, and 74B had stable COL1A2 expression by RT-PCR and moderate or low methylation levels, ranging from $38.3 \%$ to $59.0 \%$. Methylation levels of UM-SCC-1 and 23 (68.0\% and $78.0 \%)$ were higher than of UM-SCC-10B (62.9\%), although these cell lines had positive $C O L 1 A 2$ expressions. For the six COL1A2-negative cell lines (UMSCC-6, 10A, 10B, 14B, 22A, and 54), CpG site \#15 upstream of the transcription start site was methylated in $91-100 \%$. In contrast, for the cell lines with a more readily detectable message (UM-SCC-1, 2, 22B, 23, and 74B), the proportion of methylated alleles fell below $90 \%$, and the message level of COL1A2 expression was stable (Fig. 3B).

\subsection{Association of molecular markers and survival with COL1A2 methylation status}

Methylation of COL1A2 was significantly correlated with $H$-cadherin methylation $(P=0.039)$. No other molecular markers showed a significant correlation with COL1A2 methylation status (Table 1). On 
Table 1

COL1A2 Gene Methylation Status in HNSCC Primary Samples

\begin{tabular}{|c|c|c|c|}
\hline \multirow{2}{*}{$\begin{array}{l}\text { Patient and tumor } \\
\text { characteristics }(n=98)\end{array}$} & \multicolumn{2}{|c|}{ Methylation } & \multirow[b]{2}{*}{$P$-value } \\
\hline & Present $(n=46)$ & Absent $(n=52)$ & \\
\hline \multicolumn{4}{|l|}{$A g e^{\dagger}$} \\
\hline 70 and older (27) & 11 & 16 & 0.502 \\
\hline Under $70(71)$ & 35 & 36 & \\
\hline \multicolumn{4}{|l|}{$\operatorname{Sex}^{\dagger}$} \\
\hline Male (80) & 34 & 46 & 0.073 \\
\hline Female (18) & 12 & 6 & \\
\hline \multicolumn{4}{|l|}{ Smoking status ${ }^{\dagger}$} \\
\hline Smoker (68) & 33 & 35 & 0.666 \\
\hline Nonsmoker (30) & 13 & 17 & \\
\hline \multicolumn{4}{|l|}{ Alcohol exposure ${ }^{\dagger}$} \\
\hline Ever (60) & 27 & 33 & 1 \\
\hline Never (38) & 19 & 19 & \\
\hline \multicolumn{4}{|l|}{ Tumor size $e^{\dagger}$} \\
\hline $\mathrm{T} 1-2(46)$ & 21 & 35 & $0.041^{*}$ \\
\hline T3-4 (52) & 25 & 17 & \\
\hline \multicolumn{4}{|l|}{ Lympho-node status ${ }^{\dagger}$} \\
\hline N0 (42) & 13 & 29 & $0.008^{* *}$ \\
\hline $\mathrm{N}+(56)$ & 33 & 23 & \\
\hline \multicolumn{4}{|l|}{ Stage $e^{\dagger}$} \\
\hline I-II (32) & 9 & 23 & $0.011^{* *}$ \\
\hline III-IV (66) & 37 & 29 & \\
\hline \multicolumn{4}{|l|}{ pl6 methylation $^{\dagger}$} \\
\hline Yes $(50)$ & 24 & 26 & 0.843 \\
\hline No (48) & 22 & 26 & \\
\hline \multicolumn{4}{|l|}{ RASSF1A methylation ${ }^{\dagger}$} \\
\hline Yes (21) & 12 & 9 & 0.331 \\
\hline No (77) & 34 & 43 & \\
\hline \multicolumn{4}{|l|}{ E-cadherin methylation ${ }^{\dagger}$} \\
\hline Yes (39) & 23 & 16 & 0.064 \\
\hline No (59) & 23 & 36 & \\
\hline \multicolumn{4}{|l|}{$H$-cadherin methylation ${ }^{\dagger}$} \\
\hline Yes (38) & 23 & 15 & $0.039^{*}$ \\
\hline No (60) & 23 & 37 & \\
\hline \multicolumn{4}{|l|}{ DAPK methylation ${ }^{\dagger}$} \\
\hline Yes (27) & 13 & 14 & 1 \\
\hline No (71) & 33 & 38 & \\
\hline \multicolumn{4}{|l|}{ MGMT methylation $^{\dagger}$} \\
\hline Yes (28) & 12 & 16 & 0.659 \\
\hline No (70) & 34 & 36 & \\
\hline \multicolumn{4}{|l|}{ DCC methylation $^{\dagger}$} \\
\hline Yes (30) & 13 & 17 & 0.666 \\
\hline No (68) & 33 & 35 & \\
\hline
\end{tabular}

univariate analysis, methylation of the COL1A2 gene was positively correlated with reduced disease-free survival ( $P=0.005$, log-rank test) (Fig. 4A). There was no significant difference in the disease-free survival of patients according to methylation patterns of the $E$ cadherin gene alone, the $H$-cadherin gene alone, or the combinations of the methylation changes of three genes (concordant pattern) (Fig. 4B, C, D). Moreover, results of multivariate Cox proportional hazard regression, which included age, sex, smoking status, alcohol exposure, and tumor stage, indicated that the group with methylation of the COL1A2 gene had a
2.104 times greater hazard than the group without methylation $(P=0.031$ ) (Table 2). Thus, COL1A2 promoter methylation is a predictor of poor outcome in patients with HNSCC.

\section{Discussion}

Differential DNA methylation at $\mathrm{CpG}$ islands has been associated with regulation of gene expression and is essential in normal development, $\mathrm{X}$-chromosome inactivation, imprinting, suppression of parasitic DNA 
A

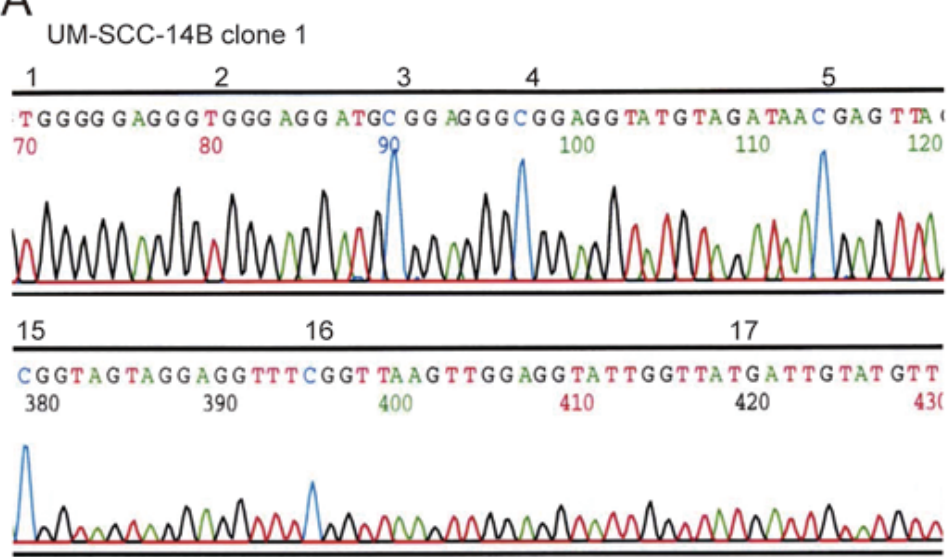

B
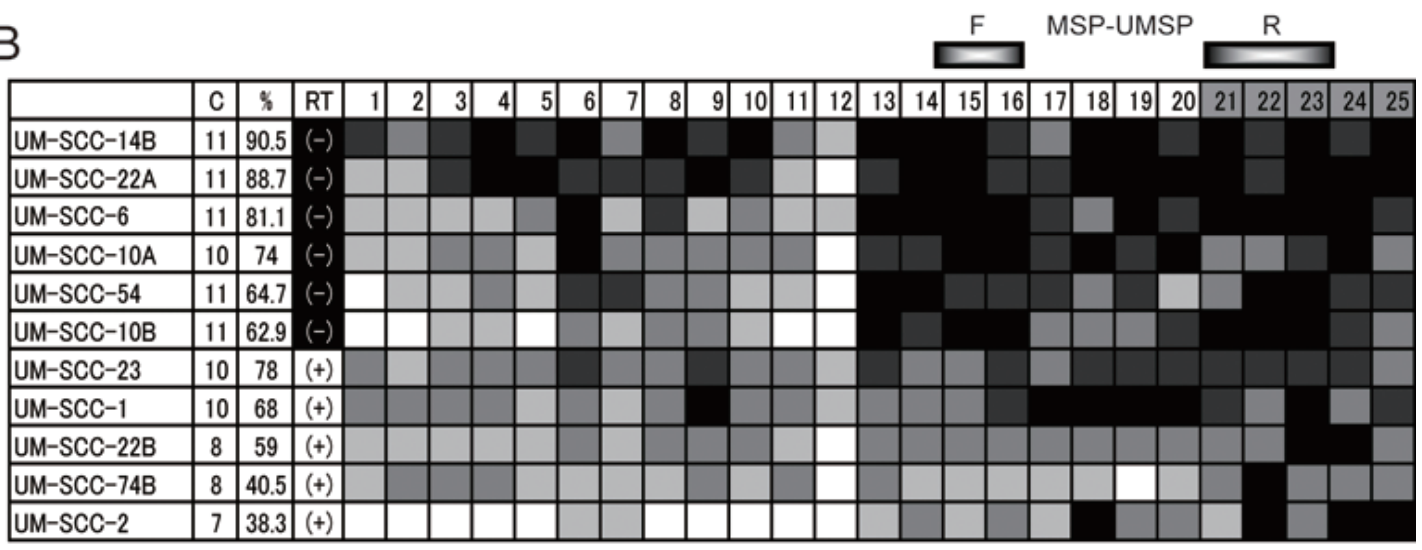

$100 \%$

$99 \sim 90 \%$

$89 \sim 50 \%$

$49 \sim 1 \% \square 0 \%$

Fig. 3. Summary of bisulfite sequencing analysis. (A) Sequencing chromatograms is demonstrated CpG island methylation after bisulfite treatment in UM-SCC-14B. (B) The shading of each cell within the figure indicates the proportion of alleles that were found to be methylated by methylation-specific sequencing. The key is shown below each panel. The numbers in the top row indicate the CpG dinucleotide positions (labeled 1-25 in Fig. 1A) in the region amplified by the bisulfite sequencing analysis primers. The locations of the MSP primer binding sites (MSP/UMSP-F and MSP/UMSP-R) used for the data in Fig. 3B are indicated by the black boxes above the figure. The cell line numbers are shown in the left column. The numbers of clones sequenced (cl) are given in the second column. The column headed RT summarizes the RT-PCR results; RT(+) signifies positive for COL1A2 expression by RT-PCR; RT(-) signifies negative for COL1A2 expression.

sequences, and cancer [27]. Methylation has practical benefits over other molecular biomarkers. First, changes in methylation occur globally within a cancer's DNA. Second, the abnormal result is a positive signal, reducing the problem of normal cell contamination [28]. There is increasing evidence showing that gene silencing due to aberrant methylation of DNA is an early event in carcinogenesis and is associated with early recurrence in some cancers [29]. The establishment of DNA methylation profiles of the primary tumor specimen itself might be a valuable tool in determining the prognosis and predicting the patient's response to therapies [30].

It is interesting that the region surrounding the COL1A2 (7q22.1) transcription start site is not a typ- ical $\mathrm{CpG}$ island. Therefore, this promoter may become methylated more easily than a protected $\mathrm{CpG}$ island promoter [12]. Sengupta et al. reported that the sequence-specific DNA-binding protein RFX (regulatory factor for X-box) could mediate the transcriptional activation of a methylated COL1A2 gene promoter that was repressed by methylation [31]. There is a binding site for the RFX family within the promoter region of the COL1A2 gene. Forward primers for MSP and UMSP bind in the segment of the promoter that contains CpG dinucleotide \#15, which corresponds to a consensus RFX-binding site [12]. RFX1 was associated with distinct sets of co-repressors on the collagen transcription start site [10]. The DNA methyl- 
A
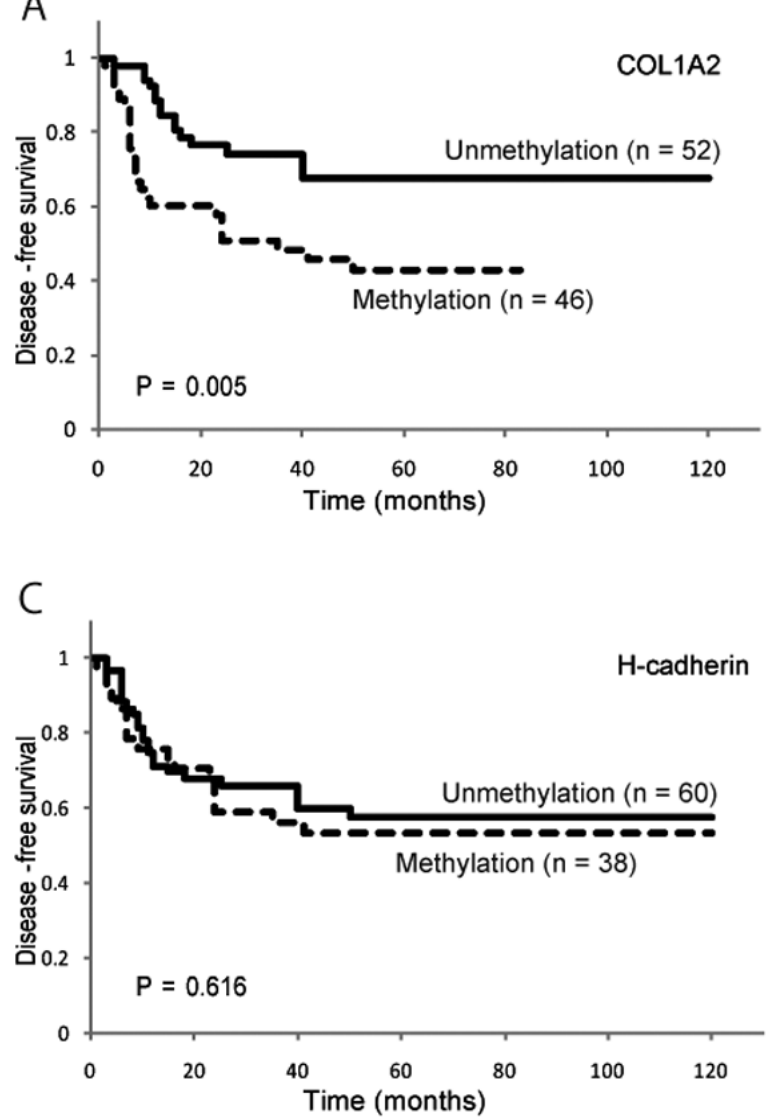

B

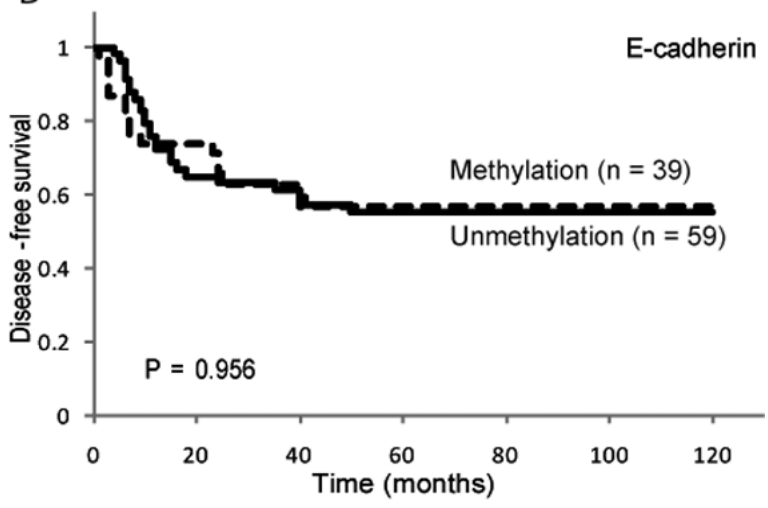

D

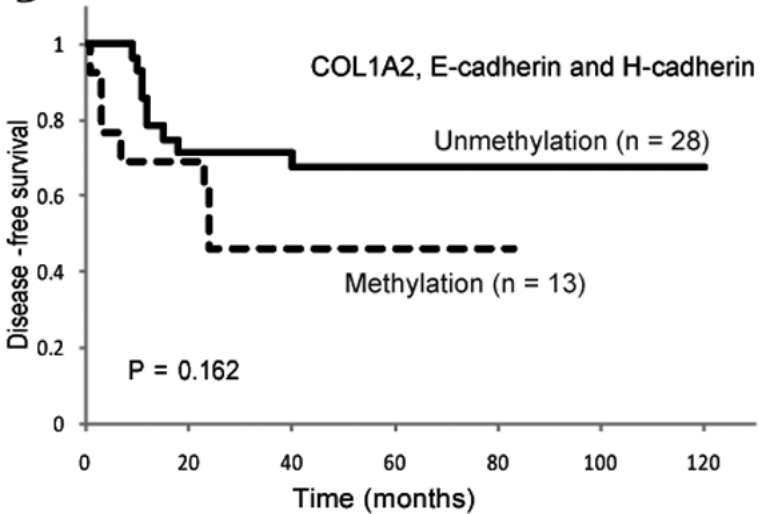

Fig. 4. Kaplan-Meier Estimates of Disease-free Survival among 98 Case Patients. Data are reported for a three-gene panel consisting of $C O L 1 A 2$ (A), E-cadherin (B), and $H$-cadherin (C). Thirteen patients had methylation of all three genes, and 28 patients had no methylation of all three genes (D).

transferase inhibitor, which inhibits DNA methylation, reduces RFX1/histone deacetylase 1 (HDAC1) binding to the collagen transcription start site. Trichostatin A stimulates the acetylation of RFX proteins and activates the collagen promoter [32]. In COL1A2 expressionsilenced cell lines, their expression could be restored by demethylation with 5-azacytidine and TSA, inferring that DNA methylation and deacetylation of histones are major regulators of COL1A2 expression.

In this regard, it is worth noting that methylation of COL1A2 and cadherin genes may not be related directly, because, to the best of our knowledge, this is the first report to show a relation between the methylation statuses of these genes in various tumors, including HNSCC. Because the exact mechanisms of the functions of COL1A2 and cadherin genes in tumorigenesis are still unknown, it will be interesting to elucidate the relationships between the expressions of COL1A2 and cadherin genes. E-cadherin, encoded by $\mathrm{CDH} 1$, which is one of the best-characterized cadherins, is the key component for adherence junctions between epithelial cells [33]. E-cadherin gene promoter methylation is associated with increased pack years smoked in HNSCC [6]. E-cadherin hypermethylation is a prognostic marker of better survival and better radiotherapy response in HNSCC $[34,35]$. H-cadherin, encoded by CDH13, has also been found to be epigenetically silenced by promoter methylation in many types of tumors, including lung cancer, breast cancer, and colorectal cancer [36]. Recently, Broch et al. reported that methylation of $p 16$ and $H$-cadherin was associated with early recurrence of stage I non-small cell lung cancer [29]. In nasopharyngeal carcinoma, $H$-cadherin was methylated in $89.7 \%$ of cases [37]. However, the roles of the $H$-cadherin gene have not been elucidated in other sites of primary HNSCC tumors. Methylation of $H$-cadherin was significantly correlated with $D A P K$ methylation $(P=0.0009)$. (data not shown)

There is also evidence for COL1A2 aberrant promoter methylation in genome-wide methylation stud- 
Table 2

Multivariate analysis of factors affecting survival using Cox proportional hazards model

\begin{tabular}{|c|c|c|}
\hline \multirow[b]{2}{*}{ Variables } & \multicolumn{2}{|c|}{ Disease-free survival } \\
\hline & HR (95\% CI) & $P$ \\
\hline \multicolumn{3}{|l|}{ Age } \\
\hline 70 and older vs. $<70$ & $1.370(0.753-2.553)$ & 0.322 \\
\hline \multicolumn{3}{|l|}{ Sex } \\
\hline Male vs. Female & $0.826(0.395-1.725)$ & 0.610 \\
\hline \multicolumn{3}{|l|}{ Smoking status } \\
\hline Smoker ve. Non smoker & $0.747(0.343-1.627)$ & 0.463 \\
\hline \multicolumn{3}{|l|}{ Alcohol exposure } \\
\hline Ever vs. Never & $0.999(0.493-2.023)$ & 0.998 \\
\hline \multicolumn{3}{|l|}{ Stage } \\
\hline I, II vs. III, IV & $2.142(1.155-3.974)$ & 0.016 \\
\hline \multicolumn{3}{|l|}{ COL1A2 methylation } \\
\hline Yes vs. No & $2.104(1.069-4.144)$ & 0.031 \\
\hline
\end{tabular}

ies of cancer cells, such as colorectal cancer [12], melanoma [13], bladder cancer [14], neuroblastoma [15], medulloblastoma [16,17], breast cancer [18], and hepatoma [19]. The investigation for oncogenic mechanism by COL1A2 gene inactivation was also recently progressing. In melanoma, $C O L 1 A 2$ methylation was predominantly detected in advanced stage tumors [13]. COL1A2 gene inactivation through CpG hypermethylation may contribute to proliferation and migration activity of bladder cancer [14]. The epigenetic status of COL1A2 may reflect the developmental biology of different medulloblastoma histological and molecular subtypes [16,17]. COL1A2 hypermethylation of $\mathrm{CpG}$ islands can be a promising marker of many types of tumors.

In this study, COL1A2 expression was shown to be frequently absent in HNSCC. The increased CpG dinucleotide \#15 methylation of the COL1A2 gene is inversely correlated with COL1A2 mRNA levels. In a survey of 98 tumor tissue samples using MSP, hypermethylation of the COL1A2 promoter occurred with a high frequency $(46.9 \%)(p 16,51.0 \% ; E$-cadherin, $39.8 \% ; \mathrm{H}$ cadherin, 38.8\%; DCC, 30.6\%; MGMT, 28.6\%; DAPK, $27.6 \%$; and RASSF $1 A, 21.4 \%$ ). Thus, COL1A2 resembled other major tumor suppressor genes in the frequency of aberrant promoter methylation. More importantly, in the case of COL1A2, there was a clear effect of methylation on clinical outcome. Diseasefree survival was significantly worse in patients with methylation in COL1A2 $(P=0.005)$. On multivariate analysis, only COL1A2 methylation and clinical stage were significantly associated with poor survival when age, sex, smoking status, and alcohol intake were also considered. Thus, COL1A2 methylation appears im- portant in disease progression and in the development of high-risk HNSCC.

In conclusion, the present study showed that the COL1A2 promoter methylation profile appears to be an important marker predicting the clinical outcome of HNSCC. This information can be used to identify patients with high-risk HNSCC who may benefit from adjuvant therapy and cautious observation after the resection of primary tumors. Finally, COL1A2 can be reactivated by altering chromatin modifications with methyltransferase and histone deacetylase inhibitors, raising the promise of selective small molecule inhibitors of these enzymes as a potential therapeutic target for HNSCC.

\section{Grant support}

A Grant-in-Aid for Scientific Research (No. 2359 2524) from the Ministry of Education, Culture, Sports, Science, and Technology of Japan.

\section{Acknowledgments}

The authors would like to thank Ms. Yuko Mohri for her excellent technical support.

\section{Conflict of Interest}

None declared.

\section{References}

[1] E.E. Vokes, R.R. Weichselbaum, S.M. Lippman and W.K. Hong, Head and neck cancer, N Engl J Med 328 (1993), 184194.

[2] B. Kumar, K.G. Cordell, J.S. Lee, F.P. Worden, M.E. Prince, H.H. Tran, G.T. Wolf, S.G. Urba, D.B. Chepeha, T.N. Teknos, A. Eisbruch, C.I. Tsien, J.M. Taylor, N.J. D’Silva, K. Yang, D.M. Kurnit, J.A. Bauer, C.R. Bradford and T.E. Carey, EGFR, p16, HPV Titer, Bcl-xL and p53, sex, and smoking as indicators of response to therapy and survival in oropharyngeal cancer, J Clin Oncol 26 (2008), 3128-3137.

[3] A. Forastiere, W. Koch, A. Trotti and D. Sidransky, Head and neck cancer, N Engl J Med 345 (2001), 1890-1900.

[4] M. Rodriguez-Paredes and M. Esteller, Cancer epigenetics reaches mainstream oncology, Nat Med 17 (2011), 330-339.

[5] T.S. Wong, M.W. Man, A.K. Lam, W.I. Wei, Y.L. Kwong and A.P. Yuen, The study of p16 and p15 gene methylation in head and neck squamous cell carcinoma and their quantitative evaluation in plasma by real-time PCR, Eur J Cancer 39 (2003), 1881-1887. 
[6] M. Hasegawa, H.H. Nelson, E. Peters, E. Ringstrom, M. Posner and K.T. Kelsey, Patterns of gene promoter methylation in squamous cell cancer of the head and neck, Oncogene 21 (2002), 4231-4236.

[7] S.M. Dong, D.I. Sun, N.E. Benoit, I. Kuzmin, M.I. Lerman and D. Sidransky, Epigenetic inactivation of RASSF1A in head and neck cancer, Clin Cancer Res 9 (2003), 3635-3640.

[8] J.G. Herman, J.R. Graff, S. Myohanen, B.D. Nelkin and S.B. Baylin, Methylation-specific PCR: a novel PCR assay for methylation status of CpG islands, Proc Natl Acad Sci USA 93 (1996), 9821-9826.

[9] J. Myllyharju and K.I. Kivirikko, Collagens, modifying enzymes and their mutations in humans, flies and worms, Trends Genet 20 (2004), 33-43.

[10] P.K. Sengupta, J. Fargo and B.D. Smith, The RFX family interacts at the collagen (COL1A2) start site and represses transcription, J Biol Chem 277 (2002), 24926-24937.

[11] M. Ponticos, D. Abraham, C. Alexakis, Q.L. Lu, C. Black, T. Partridge and G. Bou-Gharios, Col1a2 enhancer regulates collagen activity during development and in adult tissue repair, Matrix Biol 22 (2004), 619-628.

[12] P.K. Sengupta, E.M. Smith, K. Kim, M.J. Murnane and B.D. Smith, DNA hypermethylation near the transcription start site of collagen alpha2(I) gene occurs in both cancer cell lines and primary colorectal cancers, Cancer Res 63 (2003), 1789-1797.

[13] Y. Koga, M. Pelizzola, E. Cheng, M. Krauthammer, M. Sznol, S. Ariyan, D. Narayan, A.M. Molinaro, R. Halaban and S.M. Weissman, Genome-wide screen of promoter methylation identifies novel markers in melanoma, Genome Res 19 (2009), 1462-1470.

[14] K. Mori, H. Enokida, I. Kagara, K. Kawakami, T. Chiyomaru, S. Tatarano, K. Kawahara, K. Nishiyama, N. Seki and M. Nakagawa, CpG hypermethylation of collagen type I alpha 2 contributes to proliferation and migration activity of human bladder cancer, Int J Oncol 34 (2009), 1593-1602.

[15] H. Caren, A. Djos, M. Nethander, R.M. Sjoberg, P. Kogner, C. Enstrom, S. Nilsson and T. Martinsson, Identification of epigenetically regulated genes that predict patient outcome in neuroblastoma, BMC Cancer 11 (2011), 66

[16] E.C. Schwalbe, J.C. Lindsey, D. Straughton, T.L. Hogg, M. Cole, H. Megahed, S.L. Ryan, M.E. Lusher, M.D. Taylor, R.J. Gilbertson, D.W. Ellison, S. Bailey and S.C. Clifford, Rapid diagnosis of medulloblastoma molecular subgroups, Clin Cancer Res 17 (2011), 1883-1894.

[17] J.A. Anderton, J.C. Lindsey, M.E. Lusher, R.J. Gilbertson, S. Bailey, D.W. Ellison and S.C. Clifford, Global analysis of the medulloblastoma epigenome identifies disease-subgroupspecific inactivation of COL1A2, Neuro Oncol 10 (2008), 981-994.

[18] L.A. Loss, A. Sadanandam, S. Durinck, S. Nautiyal, D. Flaucher, V.E. Carlton, M. Moorhead, Y. Lu, J.W. Gray, M. Faham, P. Spellman and B. Parvin, Prediction of epigenetically regulated genes in breast cancer cell lines, BMC Bioinformatics 11 (2010), 305.

[19] T. Chiba, O. Yokosuka, K. Fukai, Y. Hirasawa, M. Tada, R. Mikata, F. Imazeki, H. Taniguchi, A. Iwama, M. Miyazaki, T. Ochiai and H. Saisho, Identification and investigation of methylated genes in hepatoma, Eur J Cancer 41 (2005), 11851194.

[20] N.H. Park, B.M. Min, S.L. Li, M.Z. Huang, H.M. Cherick and J. Doniger, Immortalization of normal human oral keratinocytes with type 16 human papillomavirus, Carcinogenesis 12 (1991), 1627-1631.
[21] K. Misawa, Y. Ueda, T. Kanazawa, Y. Misawa, I. Jang, J.C. Brenner, T. Ogawa, S. Takebayashi, R.A. Grenman, J.G. Herman, H. Mineta and T.E. Carey, Epigenetic inactivation of galanin receptor 1 in head and neck cancer, Clin Cancer Res 14 (2008), 7604-7613.

[22] Z. Jin, Y. Cheng, A. Olaru, T. Kan, J. Yang, B. Paun, T. Ito, J.P. Hamilton, S. David, R. Agarwal, F.M. Selaru, F. Sato, J.M. Abraham, D.G. Beer, Y. Mori, Y. Shimada and S.J. Meltzer, Promoter hypermethylation of CDH13 is a common, early event in human esophageal adenocarcinogenesis and correlates with clinical risk factors, Int J Cancer 123 (2008), 23312336.

[23] T. Martone, A. Gillio-Tos, L. De Marco, V. Fiano, M. Maule, A. Cavalot, M. Garzaro, F. Merletti and G. Cortesina, Association between hypermethylated tumor and paired surgical margins in head and neck squamous cell carcinomas, Clin Cancer Res 13 (2007), 5089-5094.

[24] H.L. Park, M.S. Kim, K. Yamashita, W. Westra, A.L. Carvalho, J. Lee, W.W. Jiang, J.H. Baek, J. Liu, M. Osada, C.S. Moon, J.A. Califano, M. Mori and D. Sidransky, DCC promoter hypermethylation in esophageal squamous cell carcinoma, Int J Cancer 122 (2008), 2498-2502.

[25] C. Buttner, A. Skupin and E.P. Rieber, Transcriptional activation of the type I collagen genes COL1A1 and COL1A2 in fibroblasts by interleukin-4: analysis of the functional collagen promoter sequences, J Cell Physiol 198 (2004), 248-258.

[26] M. H. Katz, Multivariable Analysis: A Practical Guide for Clinicians and Public Health Researchers, in: Setting up a multivariable analysis, Cambridge University Press, Cambridge, 2011, pp. 93-117.

[27] J.G. Herman and S.B. Baylin, Gene silencing in cancer in association with promoter hypermethylation, $N$ Engl J Med 349 (2003), 2042-2054.

[28] D.R. Yates, I. Rehman, M.F. Abbod, M. Meuth, S.S. Cross, D.A. Linkens, F.C. Hamdy and J.W. Catto, Promoter hypermethylation identifies progression risk in bladder cancer, Clin Cancer Res 13 (2007), 2046-2053.

[29] M.V. Brock, C.M. Hooker, E. Ota-Machida, Y. Han, M. Guo, S. Ames, S. Glockner, S. Piantadosi, E. Gabrielson, G. Pridham, K. Pelosky, S.A. Belinsky, S.C. Yang, S.B. Baylin and J.G. Herman, DNA methylation markers and early recurrence in stage I lung cancer, N Engl J Med 358 (2008), 1118-1128.

[30] M. Esteller, Epigenetics in cancer, N Engl J Med 358 (2008), 1148-1159.

[31] P.K. Sengupta, M. Ehrlich and B.D. Smith, A methylationresponsive $\mathrm{MDBP} / \mathrm{RFX}$ site is in the first exon of the collagen alpha2(I) promoter, J Biol Chem 274 (1999), 36649-36655.

[32] Y. Xu, P.K. Sengupta, E. Seto and B.D. Smith, Regulatory factor for X-box family proteins differentially interact with histone deacetylases to repress collagen alpha2(I) gene (COL1A2) expression, J Biol Chem 281 (2006), 9260-9270.

[33] D.G. Huntsman, F. Carneiro, F.R. Lewis, P.M. MacLeod, A. Hayashi, K.G. Monaghan, R. Maung, R. Seruca, C.E. Jackson and C. Caldas, Early gastric cancer in young, asymptomatic carriers of germ-line E-cadherin mutations, $N$ Engl J Med 344 (2001), 1904-1909.

[34] C.J. Marsit, M.R. Posner, M.D. McClean and K.T. Kelsey, Hypermethylation of E-cadherin is an independent predictor of improved survival in head and neck squamous cell carcinoma, Cancer 113 (2008), 1566-1571.

[35] H. De Schutter, H. Geeraerts, E. Verbeken and S. Nuyts, Promoter methylation of TIMP3 and CDH1 predicts better outcome in head and neck squamous cell carcinoma treated by radiotherapy only, Oncol rep 21 (2009), 507-513. 
[36] K.O. Toyooka, S. Toyooka, A.K. Virmani, U.G. Sathyanarayana, D.M. Euhus, M. Gilcrease, J.D. Minna and A.F. Gazdar, Loss of expression and aberrant methylation of the CDH13 (H-cadherin) gene in breast and lung carcinomas, Cancer Res 61 (2001), 4556-4560.
[37] D. Sun, Z. Zhang, N. Van do, G. Huang, I. Ernberg and L. $\mathrm{Hu}$, Aberrant methylation of $\mathrm{CDH} 13$ gene in nasopharyngeal carcinoma could serve as a potential diagnostic biomarker, Oral oncol 43 (2007), 82-87. 